\title{
Nature and Politics
}

\author{
Jeffrey C. Isaac
}

The broad theme of "nature and politics" has been ubiquitous at least since Aristotle's Politics, the fourth century BCE text often considered the founding work of political science. Long before "political science" took the distinct disciplinary and institutional forms with which we are familiar, the effort to understand the sources and the range of political experience was typically linked to reflection on naturethe nature of politics, the nature of human beings, the nature of existence, and the nature of "nature" itself. In contemporary, post-World War II political science in the United States, much of this reflection about nature has until recently been linked to the work of Leo Strauss and his followers, who saw themselves as heirs to a philosophical discourse at odds with modern social science. At the same time, serious consideration of nature as a theme of political science never disappeared and in recent decades has dramatically expanded. (And of course interpretations of the science of nature, i.e., "science," have been at the center of political science, especially since the advent of behavioralism.) One source of this expansion of interest in nature has no doubt been the growing politicization of "the environment" and heightened attention to the natural world as both the setting in which human interaction takes place and the object of extraordinary human transformation and degradation. Another source has been the politicization of identitiesrace, gender, sexuality - that had long been considered natural and whose contestation raised anew questions about "human nature" and its limits, variations, and transformations. A third source has clearly been the technological and theoretical development of "the natural sciences" themselves, and the growth of new discourses - evolutionary psychology, behavioral economics, neuroscience-that raise new questions about the complex relationships between the non-human dimensions of nature-physics, chemistry, biology and especially neurobiology—and human individuals and the social worlds that human individuals inhabit.

As this issue was taking shape in the course of the ordinary operations of our journal, two events that I am tempted to describe as extraordinary but that are becoming increasingly ordinary very visibly and audibly raised the stakes of the nature and politics theme-August 2012's Hurricane Isaac, which beseiged the Gulf Coast of the United States, and October 2012's Hurricane Sandy, which devastated large areas of the Caribbean before wreaking havoc on the Mid-Atlantic and Northeastern United States. The images of entire neighborhoods being swept away by storm surges and floods, and of the Breezy Point, Queens neighborhood that was literally burned to the ground by storm-caused fires, dramatically underscored that human beings and human societies are very much a part of nature-indeed a small part of a nature that surely eludes human control even as it is perpetually liable to human transformation and degradation. Such "natural disasters" accentuate the fact that we inhabit a carbonbased natural world subject to the physics of force and the chemistry of fire. They also vividly remind us that we are biological creatures who live by virtue of the intricate workings of our respiratory, digestive, pulmonary, and neurological systems; who die when we lack fresh air to breath, fresh water to drink, and fresh food to eat; and who suffer when we are exposed to the elements-fires, violent floods, extreme temperatures, as well as to the explosions, fumes, and poisons produced by our technologically advanced society.

What do such observations have to do with political science? A lot. At the most obvious level, they relate to the fundamental fact that all of our politics takes for granted the continued existence of a physical, chemical and biological world whose ecological sustainability has been widely called into question by climate scientists, risk analysts, and a growing number of journalists, political activists, and public officials (see Mayor Michael Bloomberg of New York City). The challenges of managing climate change, and of sustainably governing the air, soil, water, fisheries, forests, and natural resources that constitute not simply our environment but our world, are political challenges, as we highlighted in our March 2011 issue, which featured an award-winning article by Robert O. Keohane and David G. Victor on "The Regime Complex for Climate Change.” And these challenges are receiving increasing attention from political scientists who study "environmental politics" and also food politics and oil politics (see this issue's fascinating Critical Dialogue between Pauline Jones Luong and Miriam R. Lowi) and "resource wars" and global politics, civil wars and the politics of migration, the politics of borders, and the politics of national security and the growing field of "human security." Our special book review section on 
nature and politics offers one glimpse into the extensive work by political scientists on these themes.

In a broader way this is also a topic that links most of this issue's articles and essays.

The thematic organization of this issue of Perspectives on Politics originated when two interesting texts came across my desk within weeks of one another: Peter K. Hatemi and Rose McDermott's edited volume Man Is by Nature a Political Animal: Evolution, Biology, and Politics and John R. Hibbing's "Ten Misconceptions Concerning Neurobiology and Politics." Hatemi and McDermott's volume features research on political psychology by a prominent cast of political and social scientists working on this theme from a neurobiological perspective. And Hibbing's essay was written in a more discursive vein, in the effort to engage critics of this neurobiological perspective and to defend it from its most common criticisms. (Hibbing is also a contributor to the Hatemi and McDermott volume.) We thus decided to feature symposia on these texts, both because they are interesting and important and because they resonate with a growing interest in work at the intersection of neurobiology and so-called behavioral science, which has gained the attention of funding agencies; has recently been credited in some quarters with informing the 2012 Obama reelection strategy; and has perhaps played some role in Obama's recently announced decision to support a Human Genome-like project to map the human brain.

The book symposium includes five commentatorsC. Fred Alford, Claire Rasmussen, Leslie Paul Thiele, Evan Charney, and John G. Gunnell-who work at the intersection of political psychology and political theory. And the symposium on Hibbing's essay includes eight commentators-Kay Lehman Schlozman, George Marcus, Troy Duster, Larry Arnhart, Ange-Marie Hancock, William E. Connolly, Linda M.G. Zerilli, and Anne Jaap Jacobson-and a rejoinder by Hibbing. It is difficult to sum up the range of perspectives advanced in these symposia. Many of the contributors raise questions about whether recent political science drawing on neurobiology has given sufficient weight to the emergent and interpretive character of social phenomena and their irreducibility to the neurobiological or psychological dispositions of individuals. At the same time, a number of the commentators insist that this new research sheds important light on the sub-rational and affective dimensions of political orientations and behaviors. These two symposia ought to be read together, as an extended conversation among over a dozen political and social scientists about the philosophical, conceptual, theoretical, and political dimensions of recent work on neurobiology and politics. While Steven Pinker's The Better Angels of Our Nature: Why Violence Has Declined is not strictly a work of neurobiology, Pinker is a world renowned cognitive scientist and experimental psychologist, and his book extends themes previously developed in his 1997 How the Mind Works and his 2002 The Blank Slate: The Modern Denial of Human Nature. Jennifer Mitzen's review essay on Pinker-one of this issue's "Undisciplined" reviews — can thus usefully be read alongside the symposia on neurobiology. So too can Vivien E. Schmidt's review of Sven Steinmo's The Evolution of Modern States: Sweden, Japan, and the United States which in a different way considers the analogical and theoretical relevance of evolutionary biology to political science.

These discussions link nicely with two of our research articles that deal with political psychology more generally. Emilie M. Hafner-Burton, D. Alex Hughes, and David G. Victor's "The Cognitive Revolution and the Political Psychology of Elite Decision Making" provides a synthetic overview of recent work in cognitive psychology and behavioral economics that builds upon Herbert Simon's classic work on "bounded rationality" and Amos Tversky and Daniel Kahneman's work on "prospect theory," and develops a sophisticated model of the way experienced elites process information and make decisions. They argue that "Highly experienced elites are more likely to exhibit the attributes of rational decision-making ... [and] to be more skilled in strategic bargaining than [those] with less germane experience. However, elites are also more likely to suffer over-confidence, which degrades decision-making skills." They then illustrate this theoretical argument through a brief paired comparison of US foreign policymaking toward North Korea, contrasting the diplomatic negotiations of relatively inexperienced policy makers in 2002 with those of more experienced policy makers in 2006. While these case studies are relatively brief discussions that serve the paper's broader conceptual and programmatic purposes, this issue contains three other major discussions that expand on the complex dynamics of foreign policy decision making in ways consistent with HafnerBurton, Hughes, and Victor's cognitivist approach: Jon Western's "From Wars of Choice to the Mistakes of Wars: Presidential Decision Making and the Limits of Democratic Accountability"; Roland Paris's "Afghanistan: What Went Wrong?"; and our Symposium on Frank Harvey's Explaining the Iraq War: Counterfactual Theory, Logic and Evidence, which features spirited commentary by Adeed Dawisha, John Ehrenberg, Bruce Gilley, Stephen M. Walt, and Elizabeth Saunders. These pieces feature exceptionally sharp and nuanced discussions of the complex and dynamic relationships among ideological and policy commitments, situational learning, and strategic decision making over time that characterize foreign policy making in response to crises and especially in decisions of war and peace.

If these discussions center on the psychology of elite decision making, Wendy Pearlman's "Breaking the Barrier of Fear: Emotions and Mobilization in the Arab Uprisings" centers on what might be called the social psychology of citizen rebellion against perceived injustice. Drawing 
on extensive primary data-press reports, personal testimonials, photographs, videos, and audio recordings in Arabic, English, and French-Pearlman adds to the growing body of literature on the sources and dynamics of the Arab Spring. (She explicitly engages Kurt Weyland's “The Arab Spring: Why the Surprising Similarities with the Revolutionary Wave of 1848?" published in our December 2012 issue.) As she writes: "For decades under authoritarian regimes, most citizens in the Arab world did not engage in public dissent for fear of danger and doubt about its ability to produce change. In 2011, however, many defied that very calculus. ... If not new values or low costs, what pushed many people from relative resignation to resistance? A striking number of people in the Arab world explain this puzzle with the expression inkasar hajez al-khawf - 'The barrier of fear has broken.' Their self-understandings call for an approach to microfoundations that, distinct from utility maximization or values, focuses on emotions. Emotions are noninstrumental, subjective, evaluative experiences that are evoked by external or mental events and carry both physiological changes and action tendencies. Emotions of fear, sadness, and shame encourage individuals to avoid risk, prioritize security, and pessimistically submit to circumstances that they find threatening. Emotions of anger, joy, and pride increase risk acceptance, prioritization of dignity, and an optimistic readiness to engage in resistance." Pearlman's article is an empirically rich account of important aspects of the Arab Spring that integrates work in comparative politics, political psychology, and social movement theory.

Lee Ann Fujii's "The Puzzle of Extra-Lethal Violence" addresses a affective orientation rather different than the empowering sense of indignation analyzed by Pearlmanthe disposition to mutilate, burn, lynch, rape, disfigure and massacre other people in ways that exceed any conventional political or rational calculus. Violence is an ever-present feature of political life in times of peace (read "law and order") and in times of war. What concerns Fujii are especially vivid and yet apparently politically superfluous forms of violence that have occurred in sub-Saharan African conflicts in Rwanda, Liberia, and the Sudan but also in places ranging from My Lai and Nanking to Tulsa and East St. Louis, and that seem to be an everpresent possibility during civil wars. Drawing on the work of Murray Edelman, Richard Merelman, and Peter Burke, Fujii develops a constructivist account of the social psychology of extra-lethal violence, arguing that such performative acts, whether spectacular or carnivalesque, simultaneously elevate their perpetrators and degrade their victims.

If Fujii analyzes the social construction of a particularly grisly modality of violence-nicely expanding on some of the themes discussed in our March 2012 issue-Dustin Ells Howes's "The Failure of Pacifism and the Success of Nonviolence" centers on the social construction of nonviolence as a means of pursuing justice and as an end of a good society. Howes's article offers a normative defense of an ethic of nonviolence that he calls "pragmatic pacifism." Drawing on work in normative political theory, the history of political thought, international relations scholarship, and contemporary history-at one point Howes notes, aptly, that his approach "blurs the distinction between empirical political science and political theory"Howes argues that practices of nonviolence have become increasingly prevalent and effective in contemporary politics. As he writes: "Even as pacifism as an ideology has failed to convince the publics of the world, a wide range of evidence points to the increasing success of nonviolence and the decreasing success and frequency of physical violence. These findings have led to a striking convergence in recent research among political scientists, sociologists and political theorists, who explain both the limits of violence and the power of nonviolence." Howes distinguishes between pacifism and nonviolence, and then argues on behalf of a synthesis that he calls "pragmatic pacifism," which "reformulates pacifism as a principled commitment to non-violence grounded in a realistic understanding of the historical record and the inherent political liabilities of violence." In developing this account, he draws extensively on Erica Chenoweth and Maria J. Stephan's recent Why Civil Resistance Works: The Strategic Logic of Nonviolent Conflict (which will be discussed in a forthcoming review essay by András Bozóki), and also on two books featured in this issue-Pinker's The Better Angels of Our Nature and Joshua S. Goldstein's Winning the War on War: The Decline of Armed Conflict Worldwide, the topic of a symposium with important commentaries by Page Fortna, John Mearsheimer, and Jack S. Levy.

This issue's final two research articles can also be seen as dealing, obliquely, with the theme of "nature and politics," for both analyze the ways that identities sometimes taken - by both protagonists and analysts — to be "natural" are in fact politically constructed.

Keisha Lindsay's "God, Gays, and Progressive Politics: Reconceptualizing Intersectionality as a Normatively Malleable Analytical Framework" engages a wide range of recent work in gender and politics dealing with the theme of "intersectionality" - the ways that social categories of gender, sexuality, race, and class intersect to shape the life chances and political identities of individuals. Lindsay argues against "the presumption that intersectional analysis is necessarily concerned with the progressive reordering of racial, gendered, and other hierarchies of power" and insists that the concept of intersectionality is better seen as a heuristic than as a means of substantive theoretical analysis or political critique. As she writes: "When I speak of intersectionality as a heuristic I mean that the concept of intersectionality illuminates how identities, social categories, and/or processes of identification and categorization gain meaning from each other but that it does not prescribe which identities, categories, or processes 
are mutually constructing. The result is that intersectional analysis can be used to make starkly different arguments, including anti-progressive ones, regarding who is disadvantaged and how to remedy their disadvantage." Lindsay illustrates this argument by analyzing the ways in which conservative African American ideologues appeal to the rhetoric of intersectionality to privilege their opposition to same-sex marriage by claiming that African Americans' "true" experience of oppression is grounded in the linkages among racism, heterophobia, classism, and antiChristian bias. She proceeds to show how these kinds of appeals to an "essential" experience in order to marginalize opponents and police the boundaries of group identity are a common feature of ethnic politics, whereby "social groups, from Sri Lankan Tamils to Northern Irish Catholics, mark out and then punish some members for being less authentic than others."

Eric Kramon and Daniel N. Posner develop a similar argument in "Who Benefits from Distributive Politics? How the Outcome One Studies Affects the Answer One Gets." While Lindsay works through the literature on intersectionality, Kramon and Posner work through the extensive recent literature on distributive politics, with a particular focus on the political economy of ethnic politics in Africa. As they aptly describe this literature, it centers on "the question of who profits from government policies and how the groups that do are able to secure the distributive outcomes that favor them." In the first instance, Kramon and Posner's contribution is primarily methodological. Noting that "progress in the field therefore depends critically on the ability of researchers to ascertain empirically who benefits from government allocation decisions," they observe that most of the work in this area is "vulnerable to a common and potentially devastating criticism: namely, that the pattern of favoritism that has been identified with respect to the outcome in question may be counterbalanced by a quite different, even opposite, pattern of favoritism with respect to other outcomes that are not being measured." They explore the problems with this research, and suggest remedies to these problems, by analyzing surveys from six African countries-Benin, Kenya, Malawi, Mali, Senegal, and Zambia — and examining variations in patterns of ethnic favoritism with respect to four different outcomes-infant survival, educational attainment, access to improved water sources, and household electrification. And they conclude in a way that echoes some of the "pluralist" arguments of an earlier generation of scholars of urban politics in the United States: "[T]he demonstration that ethnic favoritism varies across outcomes opens the door to a new research agenda aimed at identifying the political, structural, bureaucratic, historical and/or geographic reasons that might account for why political leaders choose to favor their supporters with some public and private goods rather than others."

As I've noted on previous occasions, we work hard to plan a publication schedule that allows us to package articles, essays, and reviews thematically. We do this because underscoring unifying themes is an important aspect of our editorial mission. Obviously, these thematic frameworks are editorial creations, and most of the particular things we publish could well be framed in other ways-or, as in most disciplinary journals, they could simply be published discretely, in the order in which they are accepted, without any framework or commentary. I mention this simply to highlight our distinctive editorial perspective, which we very much "own." I try to explain it in each issue, and every issue also contains a statement of our editorial philosophy. Just as importantly, this editorial perspective is a constant work in progress that evolves through my own reading of published political science books and articles as well as my reading of all submissions; my correspondence with hundreds of authors; through consultation with the editorial board; through annual reports to the APSA Council; and most especially through the hard work of my incredible staff, who are true interlocutors and editorial partners. I am very pleased to thank those staff members who worked with me to produce this issue: Managing Editor James Moskowitz, Book Review Managing Editor Margot Morgan, and Editorial Assistants Laura Bucci, Adrian Florea, Peter Giordano, Emily Hilty, Rafael Khachaturian, and Brendon Westler. I am also especially pleased to be publishing the terrific article by Dustin Ells Howes, for Dustin was a Book Review Editorial Assistant during the journal's first editorial regime, when the Review was being edited by Susan Bickford and Greg McAvoy at the University of North Carolina, Chapel Hill. When Margot, James, and I first brought the Book Review to Indiana University back in 2005, Dustin was amazingly helpful. Indeed, he traveled to Bloomington to help us set up the database. Since that time he has earned his Ph.D., published articles and a book, and become an Assistant Professor. He has also done some fine reviewing for our journal. It is a pleasure to welcome him back to the pages of Perspectives as an article author. 


\section{Statement of Mission and Procedures}

Perspectives on Politics seeks to provide a space for broad and synthetic discussion within the political science profession and between the profession and the broader scholarly and reading publics. Such discussion necessarily draws on and contributes to the scholarship published in the more specialized journals that dominate our discipline. At the same time, Perspectives seeks to promote a complementary form of broad public discussion and synergistic understanding within the profession that is essential to advancing scholarship and promoting academic community.

Perspectives seeks to nurture a political science public sphere, publicizing important scholarly topics, ideas, and innovations, linking scholarly authors and readers, and promoting broad reflexive discussion among political scientists about the work that we do and why this work matters.

Perspectives publishes work in a number of formats that mirror the ways that political scientists actually write:

Research articles: As a top-tier journal of political science, Perspectives accepts scholarly research article submissions and publishes the very best submissions that make it through our double-blind system of peer review and revision. The only thing that differentiates Perspectives research articles from other peer-reviewed articles at top journals is that we focus our attention only on work that in some way bridges subfield and methodological divides, and tries to address a broad readership of political scientists about matters of consequence. This typically means that the excellent articles we publish have been extensively revised in sustained dialogue with the editor-me-to address not simply questions of scholarship but questions of intellectual breadth and readability.

"Reflections" are more reflexive, provocative, or programmatic essays that address important political science questions in interesting ways but are not necessarily as systematic and focused as research articles. These essays often originate as research article submissions, though sometimes they derive from proposals developed in consultation with the editor in chief. Unlike research articles, these essays are not evaluated according to a strict, doubleblind peer review process. But they are typically vetted informally with editorial board members or other colleagues, and they are always subjected to critical assessment and careful line-editing by the editor and editorial staff.

Scholarly symposia, critical book dialogues, book review essays, and conventional book reviews are developed and commissioned by the editor in chief, based on authorial queries and ideas, editorial board suggestions, and staff conversations.

Everything published in Perspectives is carefully vetted and edited. Given our distinctive mission, we work hard to use our range of formats to organize interesting conversations about important issues and events, and to call attention to certain broad themes beyond our profession's normal subfield categories.

For further details on writing formats and submission guidelines, see our website at http://www.apsanet.org/ perspectives/ 